\title{
Computational and test of the polypropylene blade models 'output characteristics of the wind turbine
}

\author{
${ }^{1}$ Balakumaran.CD, ${ }^{2}$ Karthikeyan.M \\ ${ }^{I}$ Department of Mechanical Engineering, Karpagam University, Coimbatore-641006 \\ 2Department of Mechanical Engineering Karpagam University Coimbatore-641010
}

\begin{abstract}
The simulation document is a live template. Based on the computational simulation the output characteristics is set up for the resemble models of small scale polypropylene wind turbine blades, which are under a test system with three different setting angles at a degree of 10.5, 30.5 and 50.5. Nrel 846 is taken to estimate the pressure created, torque coefficient acting on the blade at different setting angles by using cfd. At the same time, characteristic output tests are carried out in wind tunnel system. The results show that each relative error of simulation and testing results of the model test system is less than 10\%. .It proves that the computational method is reliable and the testing results are reasonable.
\end{abstract}

Keywords: wind turbine generator, blade, wind tunnel test, (pp) polypropylene, CFD (computational fluid dynamics), NREL (national renewable energy laboratory)

\section{Introduction}

Wind Energy is one of the most popular and important alternative energy sources. Wind energy is a low cost, clean source for electricity in creating new business opportunities for production and innovation of new materials ${ }^{1}$. Wind power generation is reaching $30 \%$ growth in every year since 1994 . On the basis of blade momentum theory the blade was manufactured by hollow tapered beam to calculate the stiffness and mass matrices ${ }^{2}$. The computational analysis is to analyse the non-axial and non-uniform flow of the wind blades. These analysing software is the extension of hybrid navier stokes which is developed for helicopter rotor and propeller application of horizontal axis wind turbine ${ }^{3}$. The fatigue life and the damage factor of the composite blade estimates its life of prediction ${ }^{4}$. The author represents the output characteristics of wind blade by setting three different angles to determine the best suitable angle for power generation ${ }^{5 .}$ In this paper we are going to investigate the best setting angle of the wind turbine blade using computational fluid dynamics. By using this computational analysis, we can determine the best setting angle according to the theoretical condition. We have selected polypropylene material for its vibration frequency and stress resisting capacity. Three different angles $10.5,30.5$, and 50.5 were set to determine the best suitable angle for power generation ${ }^{5}$.

\section{Experimental Study}

The aerdynamic performance of polyproplene material is machined in Vertical Machining Center and the design of the blade is taken from S835 model NREL Laboratory from American department of aeronautics .This model of blade is mainly selected for its rotation at an average wind speed of 3-9 m/s for the efficient power generation. The CFD investigation was done to obtain the detailed data concerning the mechanism of torque creation and pressure created in three different setting angles. In this experimental study $200 \mathrm{w}$ wind generator is taken and at the different blade setting angles of $10.5,30.5$ and 50.5 is analysed in wind turbine. The wind turbine which is installed in $20 \mathrm{mts}$ tall building and at particlar wind velocity the blade rotating speed is calculated for three setting angles polypropylene wind turbine blades. From this experimental analysis we have concluded that the less degree of angle of twist that is 10.5 degree is the best angle of setting the wind turbine blades.

Table1. Shows that the properties comparison difference between polypropylene and existing blade

\begin{tabular}{|ll|cc|}
\hline Properties & FRP & CFRP & PP \\
\hline Density & $1800 \mathrm{~kg} / \mathrm{m}^{3}$ & $1700 \mathrm{~kg} / \mathrm{m}^{3}$ & $980 \mathrm{~kg} / \mathrm{m}^{3}$ \\
\hline Von mises stress & $21.167 \mathrm{MPA}$ & $21.633 \mathrm{MPA}$ & $19.65 \mathrm{MPA}$ \\
\hline Hardness & $55 \mathrm{BHN}$ & $50 \mathrm{BHN}$ & $65 \mathrm{BHN}$ \\
\hline $\begin{array}{l}\text { Vibration } \\
\text { frequency }\end{array}$ & $81.56 \mathrm{~Hz}$ & $76.55 \mathrm{~Hz}$ & $12.55 \mathrm{~Hz}$ \\
\hline
\end{tabular}


Table 2. represents the performance wind turbine at different setting angles according to its wind velocity

\begin{tabular}{|c|c|c|c|c|}
\hline $\begin{array}{l}\text { Wind } \\
\text { velocity }\end{array}$ & $\begin{array}{l}\text { Rpm at } 10 \text { degree } \\
\text { of setting angle }\end{array}$ & $\begin{array}{lrr}\text { Rpm } & \text { at } & 10.5 \\
\text { degree } & \text { of } & \text { setting } \\
\text { angle } & & \end{array}$ & $\begin{array}{llr}\text { Rpm } & \text { at } & 30.5 \\
\text { degree } & \text { of } & \text { setting } \\
\text { angle } & & \\
\end{array}$ & $\begin{array}{lrr}\text { Rpm } & \text { at } & 50.5 \\
\begin{array}{l}\text { degree } \\
\text { angle }\end{array} & \text { of } & \text { setting } \\
& & \end{array}$ \\
\hline 6 & 350 & 340 & 330 & 310 \\
\hline 8 & 400 & 390 & 400 & 380 \\
\hline 10 & 430 & 420 & 405 & 400 \\
\hline 12 & 500 & 460 & 430 & 440 \\
\hline 14 & 560 & 500 & 520 & 550 \\
\hline
\end{tabular}

Polypropylene is one of those rare versatile polymers available. It serves double duty, both as a plastic and as a fibre. As a plastic it is used to make things like dishwasher and safe food containers. It can be done because it does not melt below $160^{\circ} \mathrm{C}$. Polypropylene has polymorphism consisting of 3 crystal structures. These 3 structures differ in their crystallography or the manner in which the chains are packed in the unit cell. PP crystals can be monoclinic $\alpha$-form, hexagonal $\beta$-form and triclinic $\gamma$-form ${ }^{6}$. Polypropylenes have unique characteristic features such as low molecular weight, high brittleness, machinablity at high melting point and hardness. No coolant is required while machining because doesn't damage the cutter. At the same time due to its heat resistance, melting of material does not occur at any case. Degradation, colour fading, bending for weather and climatic conditions will not happen at any case. Fixing into hub with normal anchoring bolts can be done simply without any specialised methods to fix it. Flapping during heavy wind is nil. For these features PP is selected as a blade material. Polypropylene is a durable material that can replace FRP for its consistency in all sorts of criteria's. PP in form sheet of size $950 \mathrm{~mm}$ length, $150 \mathrm{~mm}$ width and $50 \mathrm{~mm}$ thickness is taken. The material is machined in three stage process. The first stage $\mathrm{X}$ axis machining is done by holding the PP in vertical position and from this preliminary design is done in second stage. Using slow machining the twist and angles are accurately designed and on the final stage the hold piece to hub, tail portion are machined technically and smooth surface finishing is obtained.

Fig1. Crystal structure of polypropylene

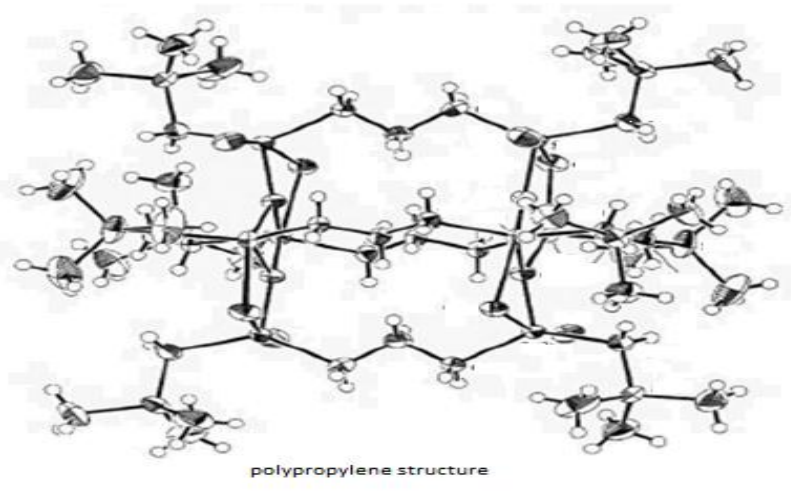

III. Results And Discussion

In the previous experimental analysis we have studied practically about the performance of wind turbine blades according to its wind velocity. From the analysis it shows that the smaller angle of setting has more performance. By taking these analysis results, we have investigated in cfd to find its torque creation, pressure creation for three different setting angles of polypropylene. The simulation and wind tunnel test results are shown below.

\section{Output power}

The output power of the wind blade for different angles are tested in wind tunnel experiment. The effective wind speed is from $3 \mathrm{~m} / \mathrm{s}$ to $16 \mathrm{~m} / \mathrm{s}$. Fig. 1 shows the output power for three different setting angles of wind blade. From this analysis the output power for wind turbine is proportional to wind speed. 
Fig 2. Power produced at different setting angles pp wind turbine

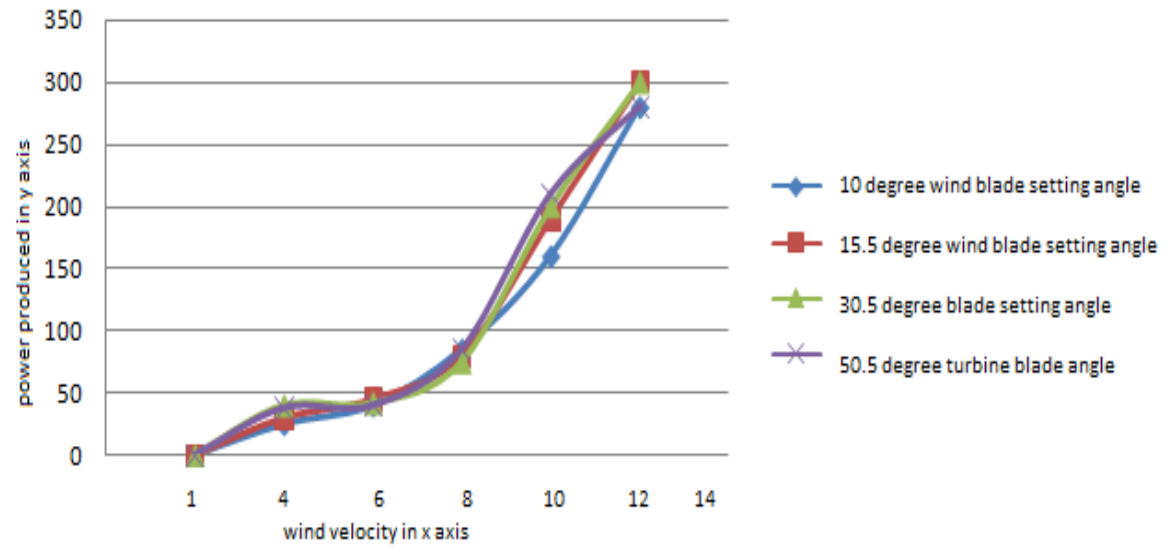

\section{Pressure acting on the blade}

Usually the pressure acting on the wind blade cannot be find out through the numerical simulation. The cfd(computational fluid dynamics) gives the thoeritical value of pressure acting on the wind blade. The pressure acting on the blade is shown below.

TABLE 3. Shows the pressure acting on the pp blade at $8 \mathrm{~m} / \mathrm{s}$ of wind velocity

\begin{tabular}{|l|l|}
\hline $\begin{array}{l}\text { Wind turbine blade setting angle } \\
\text { In degree }\end{array}$ & Pressure created \\
\hline 10 & 101.290 \\
\hline 10.5 & 101.300 \\
\hline 30.5 & 101.302 \\
\hline 50.5 & 101.324 \\
\hline
\end{tabular}

\section{Torque coefficient}

The values derived from the wind tunnel experiments of three different setting angles of wind turbine simulated in cfd are used to find out the relative errors between experimental values and simulation results. Fig. 3 shows the torque coefficient of three different setting angles of wind blade. At the point of $12 \mathrm{~m} / \mathrm{s}$ wind velocity, the torque co-efficient error for the blades are $2.3 \%, 3 \%, 3.8 \%$ and $4.5 \%$. It shows that the 10 degree angle setting of wind blade has less error and more torque co-efficient.

Fig 3. shows experimental results and simulated results of pp wind turbine

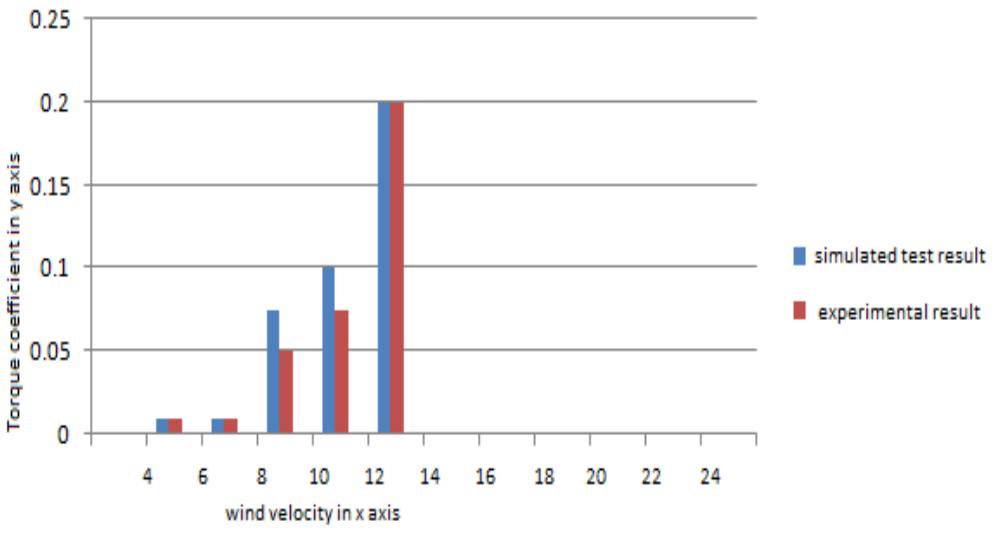

\section{Conclusion}

From the simulation and test result it shows that the smaller angle will produce more power. The cfd analysis shows that the errors between the experimental analysis and simulation analysis is very less. The expression of wind velocity and rotor turning speed is calculated for finding th torque coefficient. From this we have identified the range of angle setting of pp wind turbine. This study is also used for other wind turbine materials to create an alternative source of energy i.e.wind energy with alternative materials. 


\section{References}

[1]. Robert C., Nelson Thomas C., Corke and Hesham Othman Mehul P. Patel,SrikanthVasudevan and Terry Ng “A Smart Wind Turbine Blade Using Distributed Plasma Actuators for Improved Performance" American Institute of Aeronautics and Astronautics Paper(2008).

[2]. Nazar Muneam Mahmood, Mohammed.Kh.Abbas, "computer program to predict performance of fast running horizontal axis wind turbine to reaching the optimum design" journal of engineering science ,pp 551-557(2010).

[3]. Aniket C. Aranake, Vinod K. Lakshminarayan, Assessment of Transition Model and CFD Methodology for Wind Turbine Flows pp 1-22 (2012).

[4]. Nijssen, "fatigue life prediction and strength degradation of wind turbine rotor blade composites "pp 1-6 (2007).

[5]. Xu Baoqinga,Tian Deb," Simulation and Test of the Blade Models' Output Characteristics of Wind Turbine" pp 2051-2062 (2012).

[6]. Ivan Dobrev1, FawazMassouh,"Exploring the Flow around a Savonius Wind Turbine" pp 1-9 (2012).

[7]. Michel, "Etude de la Transition sur les Profiles d'Aile," ONERA Report 1/1578A, 1951.

[8]. Moran, An Introduction to Theoretical and Computational Aerodynamics, Dover Publications, Mineola, New York,1984.

[9]. Eppler, "A Computer Program for the Design and Analysis of Low-Speed Airofils", NASA Langley Research Center,NASA-TM80210, N80-29254, 1980.

[10]. M. Somers, Design and Experimental Results for the S809 Airfoil. NREL/SR-440-6918, Jan. 1997.

[11]. M. Somers, Design and Experimental Results for the S827 Airfoil. Airfoils, Inc., 1999.

[12]. J. A. Howard, M. Alam, and N. D. Sandham, "Two-Equation Turbulence Modelling of a Transitional Separation Bubble", Flow, Turbulence and Combustion, Vol. 63, 1999.L. Van-Ingen, “A Suggested Semi-Empirical Method 